\title{
Effects of Neoadjuvant 5-Fluorouracil and Cisplatin Therapy in Patients with Clinical Stage II/III Esophageal Squamous Cell Carcinoma
}

\author{
HIROTAKA KONISHI, HITOSHI FUJIWARA, ATSUSHI SHIOZAKI, KATSUTOSHI SHODA, \\ TOSHIYUKI KOSUGA, TAKESHI KUBOTA, KAZUMA OKAMOTO and EIGO OTSUJI
}

Division of Digestive Surgery, Department of Surgery, Kyoto Prefectural University of Medicine, Kyoto, Japan

\begin{abstract}
Background: Neoadjuvant chemotherapy (NAC) with 5-fluorouracil and cisplatin (FP) has been administered to patients with clinical stage II or III esophageal squamous cell carcinoma (ESCC). We aimed to confirm the clinical efficacy and outcomes of NAC with FP. Patients and Methods: The clinicopathological features and survival of 152 patients with clinical stage II/III ESCC who received NAC with FP followed by radical esophagectomy were analyzed. Results: The Rl/2 resection rate was higher $(p=0.06)$ and the high histological response rate was significantly lower $(p=0.05)$ in those with clinical stage III disease. Invasion depth significantly improved in those with less than cT3 (17/30. 57\%), but did not in more invasive cases $(35 / 122,29 \%)(p=0.004)$. T Factor was frequently improved in those with clinical stage II $(p=0.08)$. Five-year survival rates in clinical stage II and III were $73 \%$ and $41 \%$, respectively. A multivariate analysis identified clinical stage $(p=0.01)$ and residual tumor $(p<0.01)$ as independent prognostic factors. Conclusion: NAC with FP is effective for patients with clinical stage II ESCC, while its potency may be lower for those with clinical stage III or cT3 disease.
\end{abstract}

Esophageal carcinoma is one of the most malignant tumors due to its high metastatic and invasive potential (1). Current advances in multidisciplinary treatments such as chemotherapy and chemoradiotherapy have improved the survival of patients with locally advanced esophageal squamous cell carcinoma (ESCC) (2). Since the JCOG9907

Correspondence to: Hirotaka Konishi, MD, Ph.D., Division of Digestive Surgery, Department of Surgery, Kyoto Prefectural University of Medicine, 6028566, Kajii-cho 465, Kamigyo-ku, Kyoto city, Japan. Tel: +81 752515527, e-mail: h-koni7@koto.kpum.ac.jp

Key Words: Esophageal squamous cell carcinoma, neoadjuvant chemotherapy, 5-fluorouracil, cisplatin, docetaxel. randomized trial (3), neoadjuvant chemotherapy (NAC) with 5 -fluorouracil and cisplatin (FP) followed by surgery has become a standard radical treatment for clinical stage II and III advanced ESCC in Japan.

JCOG9907 compared preoperative FP therapy with postoperative adjuvant FP therapy, and revealed that preoperative chemotherapy followed by surgery improved overall survival without additional serious adverse events (3). The reasons proposed for better preoperative chemotherapy outcomes were preoperative down-staging, increases in complete resection, and completion of protocol treatments. In a subgroup analysis, preoperative chemotherapy was more effective in those with clinical stage II disease, for lesions involving the upper/middle third of the esophagus, and in cases of less invasion (4). Moreover, the clinical response rate of preoperative chemotherapy was not high, at $38 \%$. Although the effects of other types of chemotherapies, including taxane therapies (5-8), and chemoradiation therapy (9-12) have been reported, NAC with FP is still the standard for patients with advanced ESCC. The comprehensive clinical outcomes of NAC with FP followed by surgery have not been examined in detail since the report published by JCOG9907 $(3,13)$.

In the present study, we summarized the therapeutic outcomes of patients with clinical stage II and III advanced ESCC treated with NAC with FP followed by surgery at our hospital. Clinicopathological features and prognoses were also analyzed.

\section{Patients and Methods}

Patient characteristics. Fifty-two and one hundred patients with clinical stage II and III ESCC were treated with NAC with FP followed by surgery between July 2008 and November 2015 at the hospital of Kyoto Prefectural University of Medicine. Upper gastrointestinal endoscopy, esophagography, computed tomography, and positron emission tomography were performed for clinical staging pre and post chemotherapy. The median length of the follow-up for censored cases was 39.7 months (range=1-97 months). 
Clinical and pathological staging were performed according to the seventh edition of the tumor-node-metastasis classification of the International Union Against Cancer (14).

Pathological responses to NAC were evaluated in the primary tumor tissue by two independent clinical pathologists according to the criteria of the tenth edition of the Japanese Classification of Esophageal Cancer (15); briefly, grade 0: ineffective; grade 1: slightly effective (grade 1a or 1b: viable cancer cells account for two-thirds or one- to two-thirds of the tumor tissue); grade 2: moderately effective (viable cancer cells account for less than one-third of the tumor tissue), and grade 3: markedly effective (no viable cancer cells are evident). In the present study, the histological response of grade $1 \mathrm{~b}, 2$, or 3 was defined as a high response, while that of grade 0 or $1 \mathrm{a}$ was defined as a low response.

This study was conducted in accordance with the principles of the Declaration of Helsinki and written informed consent for the treatments and data collection was obtained from all patients. We did not seek individual ethical approval by the Facility of Science Committee at Kyoto Prefectural University of Medicine because this study was an observational study without interventions with the medical practice necessary for therapeutic purposes.

The regimen of FP therapy and eligibility. The regimen of FP therapy was repeated twice every 3 weeks according to JCOG9907 (3). A dose of $80 \mathrm{mg} / \mathrm{m}^{2} /$ day cisplatin was administered by an intravenous drip infusion on day $1 ; 800 \mathrm{mg} / \mathrm{m}^{2} /$ day 5 -fluorouracil was administered using a continuous infusion on days 1 to 5 . Appropriate pre-hydration with saline, a 5-hydroxytryptamine 3 receptor antagonist $(0.75 \mathrm{mg} /$ day palonosetron, days 1-5), aprepitant (125 mg/day, day $1 ; 80 \mathrm{mg} /$ day, days $2-3)$, and dexamethasone (6.6 $\mathrm{mg}$ /day, days 1-5) were administered. After these pre-medications, cisplatin was administered and post-hydration with an electrolyte liquid, $60 \mathrm{~g}$ of D-mannitol, and $20 \mathrm{mg}$ of furosemide (day 1) was also performed.

Eligibility criteria for this therapy were performance status 0 or 1 , creatinine level $\leq 1.5 \mathrm{mg} / \mathrm{dl}$, and adequate organ function, while there was no strict criterion for age (16). Cases of suspected clinical T4 were included if the patients were diagnosed with radically operable tumor after chemotherapy.

Surgery. Patients were indicated for total or subtotal thoracic esophagectomy and regional lymphadenectomy with curative intent; however, some patients underwent non-curative esophagectomy due to disease progression (17). Regional lymph nodes included the mediastinal and perigastric nodes, and cervical node dissection, i.e. three-field lymphadenectomy, was optional (18). Reconstruction was mostly performed using the stomach via a retrosternal route, and the colon or jejunum via a posterior mediastinum or antethoracic route was used depending on the patient state.

Statistical analysis. Statistical analyses were performed using JMP 12 software program. The chi-squared test was used to analyze clinicopathological features and chemotherapeutic responses at each clinical stage. A multivariate survival analysis was performed using Cox's proportional hazard regression model. A survival curve for cancer-specific survival was derived using the Kaplan-Meier method and compared by the stratified log-rank test. A $p$-value less than 0.05 was considered significant.
Table I. Characteristics of patients in each clinical stage (cStage).

\begin{tabular}{|c|c|c|c|}
\hline Factor & $\begin{array}{c}\text { cStage II } \\
(\mathrm{n}=52)\end{array}$ & $\begin{array}{c}\text { cStage III } \\
(\mathrm{n}=100)\end{array}$ & $p$-Value \\
\hline \multicolumn{4}{|l|}{ Age, years } \\
\hline Mean (range) & $66(48-80)$ & $66(43-78)$ & \\
\hline \multicolumn{4}{|l|}{ Gender } \\
\hline Male/female & $37 / 15$ & $83 / 17$ & 0.09 \\
\hline \multicolumn{4}{|l|}{$\mathrm{BMI}, \mathrm{kg} / \mathrm{m}^{2}$} \\
\hline Mean (range) & $\begin{array}{c}20.2 \\
(13.7-27.7)\end{array}$ & $\begin{array}{c}19.9 \\
(15.8-30.8)\end{array}$ & \\
\hline \multicolumn{4}{|l|}{ Number of cycles } \\
\hline 2 & 46 & 84 & 0.46 \\
\hline 1 & 6 & 16 & \\
\hline \multicolumn{4}{|l|}{ cT factor } \\
\hline $1-2$ & 24 & 6 & $<0.001$ \\
\hline $3-4$ & 28 & 94 & \\
\hline \multicolumn{4}{|l|}{$\mathrm{cN}$ factor } \\
\hline Absent & 38 & 1 & $<0.001$ \\
\hline Present & 14 & 99 & \\
\hline \multicolumn{4}{|l|}{ Tumor size } \\
\hline$\leq 40 \mathrm{~mm}$ & 36 & 47 & 0.007 \\
\hline$>40 \mathrm{~mm}$ & 16 & 53 & \\
\hline \multicolumn{4}{|l|}{ Location } \\
\hline $\mathrm{CeUt}$ & 11 & 17 & 0.7 \\
\hline Mt & 22 & 49 & \\
\hline LtAe & 19 & 34 & \\
\hline \multicolumn{4}{|l|}{ Clinical response } \\
\hline $\mathrm{CR} / \mathrm{PR}$ & $0 / 16$ & $0 / 42$ & 0.18 \\
\hline $\mathrm{SD} / \mathrm{PD}$ & 36 & 58 & \\
\hline \multicolumn{4}{|c|}{ Field of lymphadenectomy } \\
\hline$\leq 2$ & 39 & 63 & 0.13 \\
\hline$\geq 3$ & 13 & 37 & \\
\hline \multicolumn{4}{|c|}{ Degree of lymphadenectomy } \\
\hline D0-1 & 9 & 16 & 0.84 \\
\hline D2-3 & 43 & 84 & \\
\hline \multicolumn{4}{|l|}{ Residual tumor } \\
\hline 0 & 45 & 73 & 0.06 \\
\hline $1 / 2$ & $6 / 1$ & $18 / 9$ & \\
\hline \multicolumn{4}{|l|}{ pT factor } \\
\hline $0-2$ & 30 & 30 & $<0.001$ \\
\hline $3-4$ & 22 & 70 & \\
\hline \multicolumn{4}{|l|}{$\mathrm{pN}$ factor } \\
\hline Absent & 28 & 19 & $<0.001$ \\
\hline Present & 24 & 81 & \\
\hline \multicolumn{4}{|l|}{ pStage } \\
\hline $0-\mathrm{II}$ & 41 & 28 & $<0.001$ \\
\hline III-IV & 11 & 72 & \\
\hline \multicolumn{4}{|l|}{ Differentiation $^{1,2}$} \\
\hline Well/moderate & 35 & 70 & 0.76 \\
\hline Poor & 12 & 28 & \\
\hline \multicolumn{4}{|c|}{ Lymphatic invasion 1} \\
\hline Absent & 32 & 45 & 0.02 \\
\hline Present & 17 & 54 & \\
\hline \multicolumn{4}{|l|}{ Venous invasion $^{1}$} \\
\hline Absent & 33 & 47 & 0.02 \\
\hline Present & 16 & 52 & \\
\hline \multicolumn{4}{|c|}{ Histological response } \\
\hline $1 b-3$ & 25 & 32 & 0.05 \\
\hline $0-1 \mathrm{a}$ & 27 & 68 & \\
\hline
\end{tabular}

BMI, Body mass index; CeUt, cervival and upper thoracic; Mt, middle thoracic; LtAe, lower thoracic and abdominal; CR, complete response; PR,partial response; SD, stable disease; PD, progressive disease; ${ }^{1}$ pathological diagnosis could not be performed for four patients with $\mathrm{CR} ;{ }^{2}$ detailed differentiation was not given for three patients. 


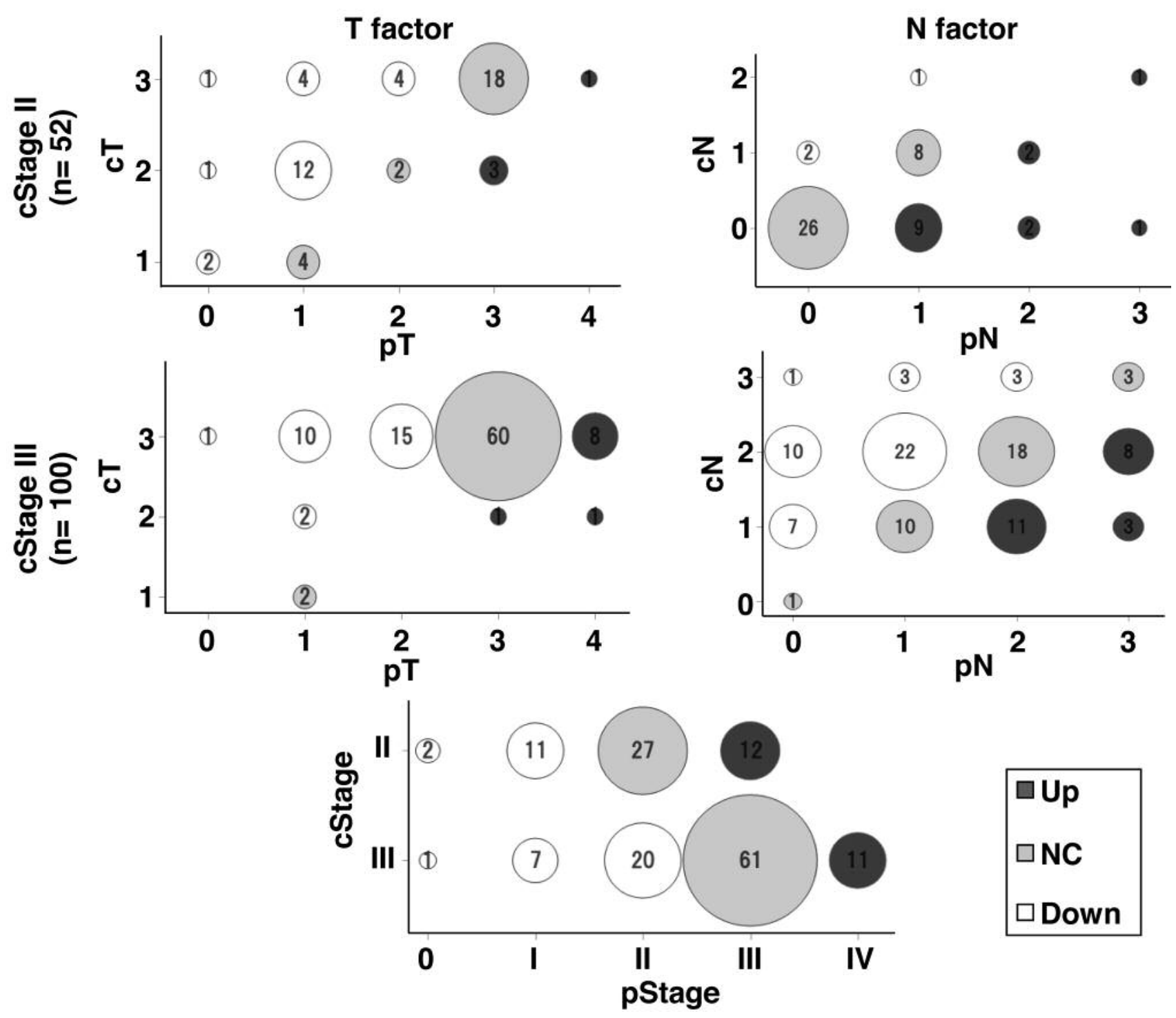

Figure 1. Relationships between clinical and pathological staging in each factor. Bubble plots show the relationships between clinical (cStage) and pathological staging ( $p$ Stage) for the $T$ factor, $N$ factor, and clinical stage. The size of bubbles and numerals represents the number of patients. 'Up' indicates disease progression; ' $N C$ ' indicates no change in staging between clinical and pathological evaluations; and 'Down' indicates improvement in staging.

\section{Results}

Patient characteristics. Patient characteristics are shown in Table I. All patients were diagnosed with ESCC, 52 and 100 patients had clinical stages II and III, respectively. Clinical and pathological $\mathrm{T} / \mathrm{N}$ factors were significantly progressive in patient with clinical stage III, while clinical response rates and the degree of lymphadenectomy were similar for both clinical stages. The R1/2 resection rate was higher (13.5 vs. $27 \%$, $p=0.06)$, and the high pathological response (1b-3) rate was significantly lower (48vs. 32\%, $p=0.05)$ in clinical stage III than in clinical stage II.
Relationships between clinical and pathological staging. Relationships between clinical and pathological staging are shown in Figure 1. The cT factor was frequently improved in patients with invasion less than cT3 (17/30. 57\%) compared with patients with cT3 lesion $(35 / 122,57 v s .29 \%)(p=0.004)$. The $\mathrm{cN}$ factor did not correlate with pathological evaluations, particularly in clinical stage III. Moreover, the clinical stage frequently remained at the same pathological stage.

Alterations of each clinical staging factor due to NAC with FP are summarized in Figure 2a. The T factor was more frequently improved by therapy in clinical stage II than in clinical stage III $(p=0.08)$, while no marked alterations were 
a

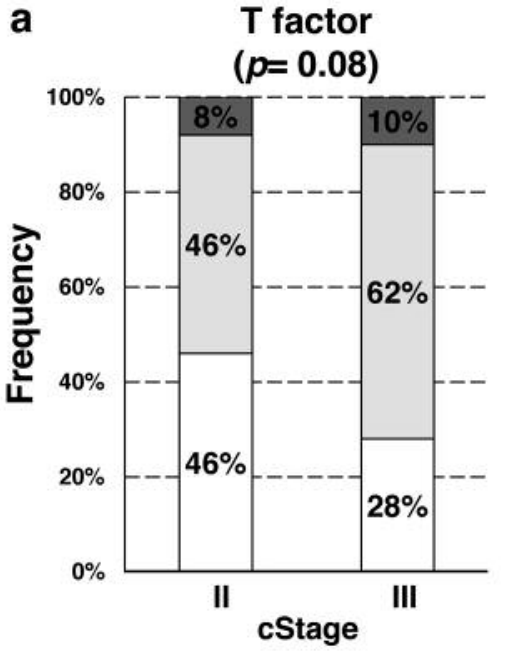

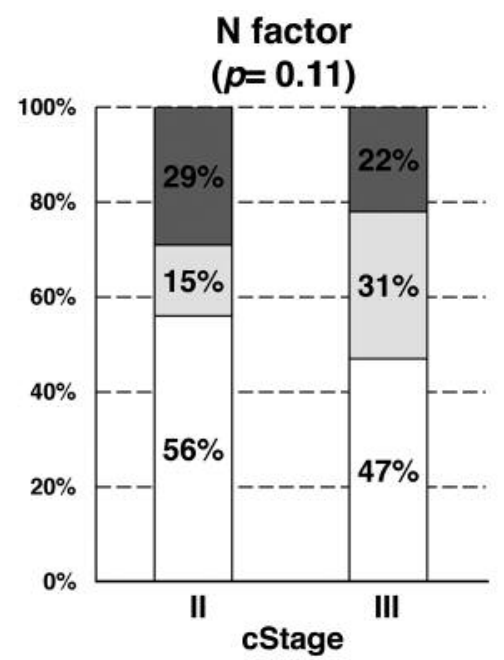

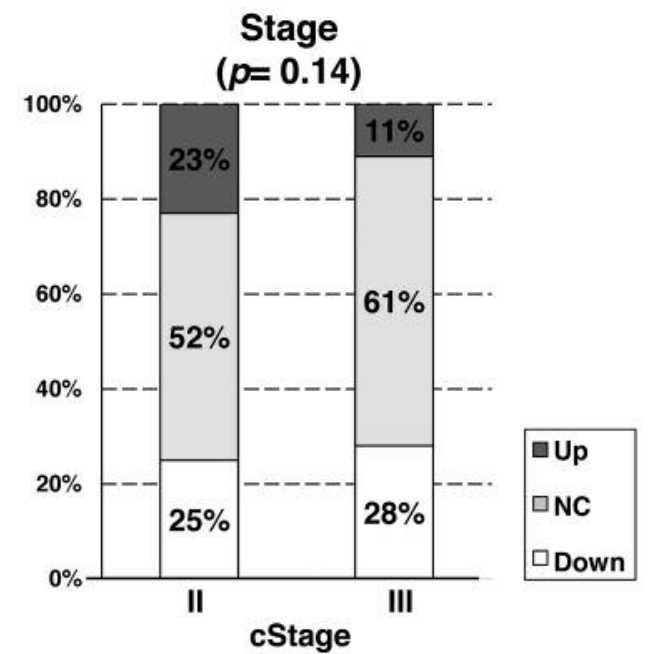

b

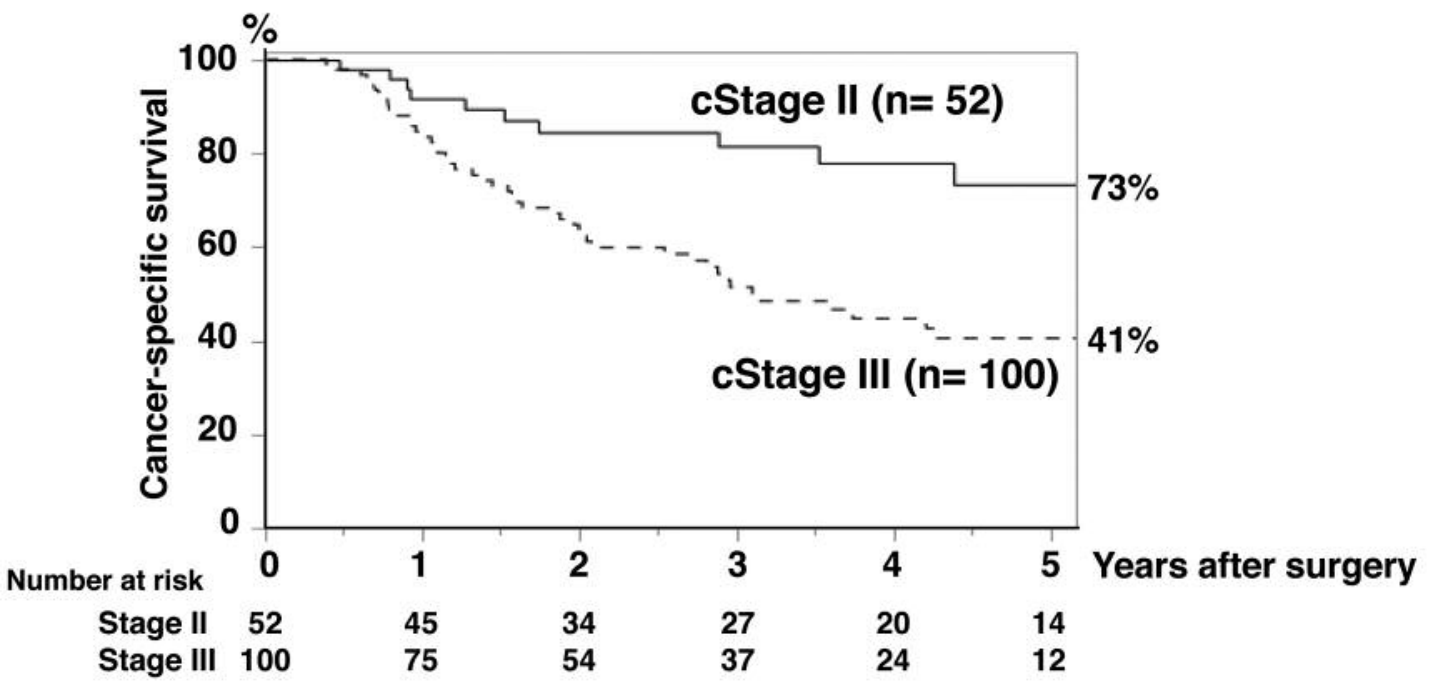

Figure 2. Alterations in staging and survival analysis. a: Alterations between clinical (cStage) and pathological staging (pStage) are summarized as column graphs for the $T$ factor, $N$ factor, and stage. Alterations were examined using the Chi-squared test. 'Up' indicates disease progression; ' $N C$ ' indicates no change in staging between clinical and pathological evaluations; and 'Down' indicates improvement in staging. $b$ : Cancerspecific survival was shown using the Kaplan-Meier method; in cStage II $(n=52)$ and cStage III $(n=100)$. Differences were compared by the stratified log-rank test.

observed in $\mathrm{N}$ factor or stage for either clinical stage $(p=0.11$ and 0.14 , respectively).

Survival analysis. Five-year cancer-specific survival rates in those with clinical stage II or III disease were 73 and $41 \%$, respectively (Figure 2b). A univariate analysis identified the clinical stage $(p<0.001)$, tumor size $(p=0.003)$, residual tumors $(p<0.001)$, the pStage $(p<0.001)$, and histological responses $(p=0.003)$ as prognostic factors (Table II), while in a multivariate analysis, the clinical stage [hazard ratio $(\mathrm{HR})=2.46,95 \%$ confidence interval $(\mathrm{CI})=1.269-5.270$, $p=0.01]$ and residual tumor $(\mathrm{HR}=3.22,95 \% \mathrm{CI}=1.826-5.615$, $p<0.001$ ) were independent prognostic factors (Table II).

\section{Discussion}

The Guidelines of Carcinoma of the Esophagus in Japan (18) have recommended NAC with FP followed by surgery as a standard therapeutic strategy for patients with clinical stage II/III ESCC according to the findings of JCOG9907 (3). However, in Western countries, the efficacy of NAC for resectable advanced esophageal cancer is currently unclear (2, 9-11). Differences in therapeutic strategies may be attributed to differences in the histological type, favored lesion site, or the importance of surgery $(1,2,9,10,19)$. Although some studies in Japan reported the efficacy of NAC with triple chemotherapy, for example, combination of 
Table II. Univariate and multivariate analyses of cancer-specific survival of patients.

\begin{tabular}{|c|c|c|c|c|c|c|}
\hline \multirow[b]{2}{*}{ Factor } & \multirow[b]{2}{*}{$\mathrm{N}$} & \multirow[b]{2}{*}{ 5-Year survival } & \multirow{2}{*}{$\frac{\text { Univariate }}{p \text {-Value }}$} & \multicolumn{3}{|c|}{ Multivariate } \\
\hline & & & & HR & $95 \% \mathrm{CI}$ & $p$-Value \\
\hline \multicolumn{7}{|l|}{ cStage } \\
\hline II & 52 & 73 & $<0.001$ & 1 & $1.269-5.270$ & 0.01 \\
\hline III & 100 & 41 & & 2.46 & & \\
\hline \multicolumn{7}{|l|}{ Location } \\
\hline CeUt & 28 & 44 & 0.82 & 1.27 & $0.570-2.726$ & 0.55 \\
\hline Mt & 71 & 51 & & 1.10 & $0.604-2.026$ & 0.76 \\
\hline LtAe & 53 & 55 & & 1 & & \\
\hline \multicolumn{7}{|l|}{ Tumor size } \\
\hline$\leq 40 \mathrm{~mm}$ & 83 & 63 & 0.003 & 1 & $0.972-3.039$ & 0.06 \\
\hline$>40 \mathrm{~mm}$ & 69 & 38 & & 1.70 & & \\
\hline \multicolumn{7}{|l|}{ Clinical response } \\
\hline $\mathrm{CR} / \mathrm{PR}$ & 58 & 50 & 0.72 & 1.37 & $0.779-2.377$ & 0.27 \\
\hline $\mathrm{SD} / \mathrm{PD}$ & 94 & 51 & & 1 & & \\
\hline \multicolumn{7}{|l|}{ Residual tumor } \\
\hline 0 & 118 & 63 & $<0.001$ & 1 & $1.826-5.615$ & $<0.00$ \\
\hline $1 / 2$ & 34 & 14 & & 3.22 & & \\
\hline \multicolumn{7}{|l|}{ pStage } \\
\hline $0-\mathrm{II}$ & 68 & 78 & $<0.001$ & - & & \\
\hline III-IV & 84 & 32 & & & & \\
\hline \multicolumn{7}{|l|}{ Differentiation $^{1}$} \\
\hline Well/moderate & 105 & 53 & 0.44 & 1 & $0.858-2.699$ & 0.14 \\
\hline Poor & 40 & 39 & & 1.54 & & \\
\hline \multicolumn{7}{|c|}{ Histological response } \\
\hline $3 / 2 / 1 \mathrm{~b}$ & 57 & 64 & 0.003 & 1 & $0.955-3.559$ & 0.07 \\
\hline $1 \mathrm{a} / 0$ & 95 & 43 & & 1.79 & & \\
\hline
\end{tabular}

CeUt, Cervival and upper thoracic; Mt, middle thoracic; LtAe, lower thoracic and abdominal;CR, complete response; PR, partial response; SD, stable disease; PD, progressive disease; HR, hazard ratio; CI, confidence interval;1 detailed differentiation was not given for seven patients.

docetaxel, cisplatin, and 5-fluorouracil (DCF) (5-8), or neoadjuvant chemoradiation therapy $(12,20)$, these findings remain controversial. Moreover, since the report published by JCOG9907, few large and comprehensive studies have been performed on the clinical application of NAC with FP to advanced ESCC (13).

In the present study, we summarized the survival of patients with clinical stage II/ III ESCC treated with NAC with FP followed by surgery. The 5-year cancer-specific survival rates in patients with clinical stage II/III disease were 73 and $41 \%$, respectively (Figure 2b). Overall survival rates were not very different from these results at 67 and $33 \%$, respectively (data not shown). In a multivariate survival analysis, clinical stage III and R1/2 resection were identified as independent prognostic factors (Table II, $p=0.01$ and $p<0.01$, respectively).

According to the Comprehensive Registry of Esophageal Cancer in Japan (2009) (21), the 5-year survival rates of patients who underwent esophagectomy were 62.7 and $41.2 \%$ for clinical stage II and III, respectively. In comparison with these findings, survival in clinical stage II was improved by NAC with FP; however, survival in clinical stage III was still poor. In the present study, although the 5year survival rates of patients with clinical stage II and III, whose pathological stage was improved to 0 -II, were better at $86 \%$ and $85 \%$, respectively, those whose pathological stage was III-IV were worse at $40 \%$ and $26 \%$, respectively (data not shown). These results suggest that patients with clinical stage III need to be treated using a more potent therapeutic strategy in order to improve the pathological stage to less than pathological stage III.

Regarding the T factor, only 9/28 (32\%) and 26/94 (28\%) of cT3 lesions in patients with clinical stage II and III were improved by NAC with FP, while 15/24 (63\%) and 2/6 (33\%) of less than cT3 lesions were improved, particularly in clinical stage II (Figure 1). Therefore, most of the cT3 lesions remained unchanged or were aggravated by NAC with FP. On the other hand, a fixed trend was not observed for the $\mathrm{N}$ factor (Figure 1). Clinical and pathological $\mathrm{N}$ factors did not correlate, and difficulties with the preoperative diagnosis of lymph node metastasis may have contributed to these results (22). 
In the present study, the number of therapeutic cycles and clinical response rates were not significantly different between clinical stage II and III patients (Table I). Furthermore, the frequency and degree of adverse events were similar in both groups (16). On the other hand, the histological response rate was significantly low in clinical stage III, and the rate of $\mathrm{R} 1 / 2$ resection was higher in clinical stage III. These results indicate a need for more potent anticancer therapies for clinical stage III, and confirm the results of the well-planned randomized JCOG9907 trial in common clinical application.

Some retrospective or prospective studies have reported the efficacy and feasibility of NAC with DCF (5-8) or neoadjuvant chemoradiation therapy $(9-12,20)$. The clinical and histological response rates, as well as the middle-term survival rates, were higher than those of NAC with FP. However, the associated adverse events were also severe, particularly with neoadjuvant chemoradiation therapy (23, 24), and these therapies will not be available to all patients due to their general condition. Therefore, it is important to select patients who require more potent therapies. We propose patients with clinical stage III or cT3 as candidates for NAC with DCF; this is now being administered to only patients with clinical stage III ESCC. The results of therapy of patients with clinical stage III disease with DCF will be useful for a future strategy for patients with advanced ESCC.

Some results obtained in the present study are controversial. These results were retrospective and obtained from only a single institution. The rate of $\mathrm{R} 1 / 2$ resection was high, particularly in clinical stage III. This may be due to the preoperative underdiagnosis of patients with non-resectable disease. In this context, the difficulties associated with a preoperative diagnosis of lymph node metastasis may affect the even distribution of clinical and pathological evaluations in the $\mathrm{N}$ factor. In survival analyses, some studies demonstrated the efficacy of NAC with DCF in clinical stage II and III (5-8); however, most studies reported the findings of clinical stage II and III together. Therefore, efficacy of and adverse events caused by NAC with DCF in patients with clinical stage II disease need to be compared with those due to NAC with FP.

Although performed on a small scale, the present retrospective study confirmed that NAC with FP is effective for patients with clinical stage II ESCC. However, its potency may be low for clinical stage III or cT3. New therapeutic strategies, including NAC with DCF, need to be examined for patients with advanced ESCC.

\section{References}

1 Hofstetter W, Swisher SG, Correa AM, Hess K, Putnam JB Jr., Ajani JA, Dolormente M, Francisco R, Komaki RR, Lara A, Martin F, Rice DC, Sarabia AJ, Smythe WR, Vaporciyan AA, Walsh GL and Roth JA: Treatment outcomes of resected esophageal cancer. Ann Surg 236: 376-384, 2002.
2 Sjoquist KM, Burmeister BH, Smithers BM, Zalcberg JR, Simes RJ, Barbour A, Gebski V and Australasian Gastro-Intestinal Trials Group: Survival after neoadjuvant chemotherapy or chemoradiotherapy for resectable oesophageal carcinoma: an updated meta-analysis. Lancet Oncol 12(7): 681-692, 2011.

3 Ando N, Kato H, Igaki H, Shinoda M, Ozawa S, Shimizu H, Nakamura T, Yabusaki H, Aoyama N, Kurita A, Ikeda K, Kanda T, Tsujinaka T, Nakamura $\mathrm{K}$ and Fukuda $\mathrm{H}$ : A randomized trial comparing postoperative adjuvant chemotherapy with cisplatin and 5-fluorouracil versus preoperative chemotherapy for localized advanced squamous cell carcinoma of the thoracic esophagus (JCOG9907). Ann Surg Oncol 19: 68-74, 2012.

4 Yokota T, Ando N, Igaki H, Shinoda M, Kato K, Mizusawa J, Katayama H, Nakamura K, Fukuda $\mathrm{H}$ and Kitagawa $\mathrm{Y}$ : Prognostic factors in patients receiving neoadjuvant 5fluorouracil plus cisplatin for advanced esophageal cancer (JCOG9907). Oncology 89(3): 143-151, 2015.

5 Hara H, Tahara M, Daiko H, Kato K, Igaki H, Kadowaki S, Tanaka Y, Hamamoto Y, Matsushita H, Nagase M and Hosoya Y: Phase II feasibility study of preoperative chemotherapy with docetaxel, cisplatin, and fluorouracil for esophageal squamous cell carcinoma. Cancer Sci 104(11): 1455-1460, 2013.

6 Nomura M, Oze I, Abe T, Komori A, Narita Y, Masuishi T, Taniguchi H, Kadowaki S, Ura T, Andoh M, Kawai R, Uemura N, Ishihara M, Tanaka T, Tajika M, Niwa Y, Muro K and Muto $\mathrm{M}$ : Impact of docetaxel in addition to cisplatin and fluorouracil as neoadjuvant treatment for resectable stage III or T3 esophageal cancer: a propensity score-matched analysis. Cancer Chemother Pharmacol 76(2): 357-363, 2015.

7 Yamashita K, Katada N, Moriya H, Hosoda K, Mieno H, Katada C, Koizumi W, Hoshi $\mathrm{K}$ and Watanabe $\mathrm{M}$ : Neoadjuvant chemotherapy of triplet regimens of docetaxel/cisplatin/5-FU (DCF NAC) may improve patient prognosis of cStage II/III esophageal squamous cell carcinoma-propensity score analysis. Gen Thorac Cardiovasc Surg 64(4): 209-215, 2016.

8 Yamasaki M, Yasuda T, Yano M, Hirao M, Kobayashi K, Fujitani K, Tamura S, Kimura Y, Miyata H, Motoori M, Shiraishi O, Makino T, Satoh T, Mori M and Doki Y: Multicenter randomized phase II study of cisplatin and fluorouracil plus docetaxel (DCF) compared with cisplatin and fluorouracil plus adriamycin (ACF) as preoperative chemotherapy for resectable esophageal squamous cell carcinoma (OGSG1003). Ann Oncol 28(1): 116-120, 2016.

9 Cao XF, He XT, Ji L, Xiao J and Lv J: Effects of neoadjuvant radiochemotherapy on pathological staging and prognosis for locally advanced esophageal squamous cell carcinoma. Dis Esophagus 22(6): 477-481, 2009.

10 Pasini F, de Manzoni G, Zanoni A, Grandinetti A, Capirci C, Pavarana M, Tomezzoli A, Rubello D and Cordiano C: Neoadjuvant therapy with weekly docetaxel and cisplatin, 5fluorouracil continuous infusion, and concurrent radiotherapy in patients with locally advanced esophageal cancer produced a high percentage of long-lasting pathological complete response: a phase 2 study. Cancer 119(5): 939-945, 2013.

11 Lv J, Cao XF, Zhu B, Ji L, Tao L and Wang DD: Long-term efficacy of perioperative chemoradiotherapy on esophageal squamous cell carcinoma. World J Gastroenterol 16(13): 16491654, 2010.

12 Nakamura K, Kato K, Igaki H, Ito Y, Mizusawa J, Ando N, Udagawa H, Tsubosa Y, Daiko H, Hironaka S, Fukuda H, Kitagawa $\mathrm{Y}$ and Japan Esophageal Oncology Group/Japan 
Clinical Oncology Group: Three-arm phase III trial comparing cisplatin plus 5-FU (CF) versus docetaxel, cisplatin plus 5-FU (DCF) versus radiotherapy with $\mathrm{CF}$ (CF-RT) as preoperative therapy for locally advanced esophageal cancer (JCOG1109, NExT study). Jpn J Clin Oncol 43(7): 752-755, 2013.

13 Matsuda S, Tsubosa Y, Sato H, Takebayashi K, Kawamorita K, Mori K, Niihara M, Tsushima T, Yokota T, Onozawa Y, Yasui H, Takeuchi $\mathrm{H}$ and Kitagawa $\mathrm{Y}$ : Comparison of neoadjuvant chemotherapy versus upfront surgery with or without chemotherapy for patients with clinical stage III esophageal squamous cell carcinoma. Dis Esophagus 30(2): 1-8, 2017.

14 Hoboken NJ: International Union Against Cancer. TNM Classification of Malignant Tumours. 7th edition. WileyBlackwell: 73-77, 2010.

15 Japanese society for oesophageal diseases: Japanese Classification of Esophageal Cancer, tenth edition. Tokyo, Japan. KANEHARA \& CO, 2007.

16 Konishi H, Fujiwara H, Shiozaki A, Hiramoto H, Kosuga T, Komatsu S, Ichikawa D, Okamoto K and Otsuji E: Effects of neutropenia and histological responses in esophageal squamous cell carcinoma with neo-adjuvant chemotherapy. Int J Clin Oncol 21(1): 95-101, 2016

17 Japanese society for oesophageal diseases: Japanese Classification of Esophageal Cancer, tenth edition. Tokyo, Japan. KANEHARA \& CO, 2007.

18 Kuwano H, Nishimura Y, Oyama T, Kato H, Kitagawa Y, Kusano M, Shimada H, Takiuchi H, Toh Y, Doki Y, Naomoto Y, Matsubara $\mathrm{H}$, Miyazaki $\mathrm{T}$, Muto $\mathrm{M}$ and Yanagisawa $\mathrm{A}$ : Guidelines for Diagnosis and Treatment of Carcinoma of the Esophagus April 2012 edited by the Japan Esophageal Society. Esophagus 12: 1-30, 2015

19 Matsuda S, Takeuchi H, Kawakubo H, Ando N and Kitagawa Y: Current Advancement in multidisciplinary treatment for resectable cStage II/III esophageal squamous cell carcinoma in Japan. Ann Thorac Cardiovasc Surg 22(5): 275-283, 2016.
20 Natsugoe S, Okumura H, Matsumoto M, Uchikado Y, Setoyama $\mathrm{T}$, Yokomakura $\mathrm{N}$, Ishigami $\mathrm{S}$, Owaki $\mathrm{T}$ and Aikou $\mathrm{T}$ : Randomized controlled study on preoperative chemoradiotherapy followed by surgery versus surgery alone for esophageal squamous cell cancer in a single institution. Dis Esophagus 19(6): 468-472, 2006.

21 The Registration Committee for Esophageal Cancer: Comprehensive Registry of Esophageal Cancer in Japan, 2009. The Japan Esophageal Society, Tokyo, 2016.

22 Yokota T, Igaki H, Kato K, Tsubosa Y, Mizusawa J, Katayama $\mathrm{H}$, Nakamura K, Fukuda $\mathrm{H}$ and Kitagawa $\mathrm{Y}$ : Accuracy of preoperative diagnosis of lymph node metastasis for thoracic esophageal cancer patients from JCOG9907 trial. Int J Clin Oncol 21(2): 283-288, 2016.

23 Bosset JF, Gignoux M, Triboulet JP, Tiret E, Mantion G, Elias D, Lozach P, Ollier JC, Pavy JJ, Mercier M and Sahmoud T: Chemoradiotherapy followed by surgery compared with surgery alone in squamous-cell cancer of the esophagus. N Engl J Med 337(3): 161-167, 1997.

24 Sathornviriyapong S, Matsuda A, Miyashita M, Matsumoto S, Sakurazawa N, Kawano Y, Yamada M and Uchida E: Impact of neoadjuvant chemoradiation on short-term outcomes for esophageal squamous cell carcinoma patients: a meta-analysis. Ann Surg Oncol 23(11): 3632-3640, 2016.

Received November 14, 2017

Revised December 3, 2017

Accepted December 8, 2017 